\title{
Effects of adjuvants on distribution and rainfastness of captan sprays on apple leaf scars to control European canker
}

\author{
R.E. Gaskin ${ }^{1}$, D.W.L. Manktelow ${ }^{2}$ and G.L. Northcott ${ }^{3}$ \\ ${ }^{1}$ Plant Protection Chemistry, , P O Box 6282, Rotorua 3043, New Zealand \\ ${ }^{2}$ Manktelow and Associates Ltd, PO Box 3415, Napier 4142, New Zealand \\ ${ }^{3}$ Northcott Research Consultants Ltd, 20 River Oaks Place, Hamilton 3200, New Zealand \\ Corresponding author: robyn.gaskin@ppcnz.co.nz
}

\begin{abstract}
Autumn leaf scars are an important pathogen infection site for European canker on apples. Trials were undertaken to evaluate the effects of adjuvants on spray coverage of new leaf scars, and determine if adjuvants could (1) impart any significant rainfastness to protectant captan sprays and (2) provide any redistribution of captan during a rain event post-leaf drop. Retention on fresh leaf scars was increased with the use of organosiliconelatex sticker adjuvants only. Rain had little effect on spray residues but these adjuvants could improve rainfastness of captan due to their effects on spray retention. Retention on stem wood and around leaf nodes was increased by up to seven-fold with the use of superspreader-type adjuvants, due to redistribution of spray runoff from leaves. High initial deposits resulted in post-rain residues on leaf scars three-fold higher than a captan spray alone. Redistribution of captan onto exposed leaf scars in rain appears likely with these adjuvants.
\end{abstract}

Keywords European canker, Neonectria ditissima, protectant fungicide sprays, captan, residues, adjuvants, rainfastness, redistribution.

\section{INTRODUCTION}

European canker, caused by Neonectria ditissima, is a concern for apple growers in New Zealand. Leaf scars are considered an important potential infection site (Scheper \& Fisher 2010) and wood lesions from successful infections can cause significant tree damage through branch and trunk girdling and removal of cankers by pruning. In autumn, leaf fall can occur over 6-12 weeks and each fresh leaf scar is a potential site for European canker infection. Protectant fungicide applications like captan are typically used over the leaf fall period. These sprays need to contact all available leaf scars and provide protection during subsequent rain events, as rain provides the main mechanism of spore dispersal (Anonymous 2009). Normally a rain event or storm results in increased leaf fall, producing more leaf scars.

This study was undertaken to investigate leaf scar coverage during a fungicide spray application, determine if spray adjuvant use could improve this, and determine if adjuvants could impart any significant rainfastness to protectant captan sprays. A second trial sought to determine if the inclusion of adjuvants in sprays applied to a foliated canopy could provide any secondary (re) 
distribution of captan during a rain event after leaf drop, to protect newly formed leaf scars.

\section{MATERIALS AND METHODS}

Fresh stems with well developed spur wood were collected from a commercial dwarf apple orchard (var. Ambrosia) and maintained with cut stems in water until used the following day. All leaves were plucked from the stems 2-4 $\mathrm{h}$ before spraying and the number of leaves per spur (i.e. the number of fresh leaf scars) was recorded. Each prepared stem (approximately $50 \mathrm{~cm}$ long) contained up to 10 spurs (approximately 70 scars). Six treatments (Table 1) were sprayed onto the sample stems, with a seventh treatment containing no adjuvant being used as a control. All treatments contained captan (Fruitfed Captan $80 \mathrm{WG}$ ) at a concentration of $480 \mathrm{~g} / 100$ litres and tartrazine dye ( $5 \mathrm{~g} /$ litre). Six adjuvants typically used in horticultural spray applications were included in the study at rates recommended by suppliers (Table 1). Sprays were applied using the PPC $_{\mathrm{NZ}}$ moving head track sprayer, through two TeeJetTX VS-10 (black) $80^{\circ}$ hollow cone nozzles at $350 \mathrm{kPa}$ to produce a fine droplet size range. The nozzles were mounted $70 \mathrm{~cm}$ apart on each side of a U-boom and were positioned to deliver approximately 300 litres/ha of spray evenly to the target. In total, 24 plucked stems were sprayed for each treatment and each stem was positioned to prevent them shading each other. Four artificial targets were sprayed in all applications to confirm the delivered spray volume.

Immediately after sprays were applied and sprayed spurs had stopped dripping, six random stems were removed from each treatment for dye recovery. All sprayed spurs on each replicate stem within each treatment were sampled; all spurs on a single stem were bulked into a single bag with the total number of spurs recorded, plus the number of leaf scars on each spur. Once leaf spurs were removed, sections cut from each stem were placed in a separate resealable plastic bag for dye recovery. Spur samples and stem samples were washed in $10 \mathrm{ml}$ and $20 \mathrm{ml}$, respectively, of distilled water containing $0.025 \%$ Du-Wett (Etec Crop Solutions Ltd) organosilicone adjuvant to maximise recovery of dye deposits. The recovered tartrazine dye was quantified spectrophotometrically (at $427 \mathrm{~nm}$ ). Spray deposits on spurs and leaf scars were determined as total amount of dye $(\mu \mathrm{g})$, normalised to $1.44 \mathrm{~kg}$ application per ha (i.e. equivalent to the nominal captan dose applied) and analysed by ANOVA to determine the significance of treatments. From this, the expected amount of captan on tissue was estimated. Stem portions were frozen immediately after washing and subsequently the diameters and lengths of each stem section were measured and the surface area of stem in each treatment calculated.

The remaining sprayed stems that had not been harvested for initial deposit analysis (18 per treatment) were placed in bright sunlight to dry for at least $1 \mathrm{~h}$ (with cut stem surfaces in water) and maintained undercover overnight. Six stems per treatment were left for a further $24 \mathrm{~h}$ and harvested as pre-rain controls for residue analysis. Twelve stems per treatment were exposed to artificial rain the day after spray application; six stems were exposed to a "moderate" rain event $(5.2 \mathrm{~mm} / \mathrm{h}$ applied for a total of $30 \mathrm{~min}$, providing $2.6 \mathrm{~mm}$ total rain) delivered using two spinnet nozzles (blue/

Table 1 Spray treatments (all contained captan (480 g/100 litres) and tartrazine dye ( $5 \mathrm{~g} /$ litre) in 300 litres/ha) applied to plucked stems.

\begin{tabular}{lllc}
\hline Adjuvant & Supplier & Adjuvant type & $\begin{array}{c}\text { Use rate } \\
(\mathrm{ml} / \mathrm{ha})\end{array}$ \\
\hline Bond Xtra & Etec Crop Solutions & organosilicone latex blend & 500 \\
Du-Wett WeatherMax & Etec Crop Solutions & organosilicone latex blend & 500 \\
Gro-Wet & Grochem & organosilicone polymer & 300 \\
Umbrella & Grochem & Terpenic polymer & 300 \\
Nu-Film-17 & Key Industries & Terpenic polymer & 300 \\
VaporGard & Key Industries & Terpenic polymer & 1000 \\
\hline
\end{tabular}


white) operating at $45 \mathrm{psi}$, and six stems were exposed to a "heavy" rain event $(15.6 \mathrm{~mm} / \mathrm{h}$ for $30 \mathrm{~min}$, providing $7.8 \mathrm{~mm}$ total rain) using two Vibranet nozzles operating at 45 psi. All stems were left under cover to dry for $24 \mathrm{~h}$ post-rain prior to sampling all leaf spurs, each carrying a known numbers of leaf scars, for captan residue analysis. All tissue samples, plus tank samples of all spray treatments, were stored frozen $(-17$ to $-19^{\circ} \mathrm{C}$ ) until analysed. Residues of captan were extracted from homogenised apple leaf scar tissue using a buffered QuEChERS ("quick, easy, cheap, effective, rugged and safe") method and purified using dispersive solid-phase extraction (Anonymous 2014). The target compound captan and surrogate recovery compound folpet were analysed by gas chromatography mass spectrometry using single ion monitoring and internal standard quantitation. The calculated method detection limits (MDLs) were $0.01 \mu \mathrm{g}$ total mass of captan and folpet.

For the second trial, M9 rootstocks (McGrath Nurseries Ltd, Hamilton) were grown in a greenhouse until they were $>1 \mathrm{~m}$ tall, healthy and fully foliated (January 2014). These shoots, on current season's growth, carried individual leaves (no spurs) and so all leaf scars were discrete and flush with the stem wood. Immediately prior to use, the potted plants were pruned back to approximately $1 \mathrm{~m}$ high and any lateral branches removed. Treatments were applied at 300 litres/ha to plants in leaf. All treatments contained captan (Fruitfed Captan 80WG) at a concentration of $960 \mathrm{~g} / 100$ litres and tartrazine dye (6 g/litre). Three adjuvants, representing three different adjuvant classes, were included in the study: $\mathrm{Du}-$ Wett WeatherMax, Gro-Wet and Nu-Film-17. The adjuvants were used at elevated concentrations to promote spray run-off from leaves. Sprays were applied through two TXVS3 (yellow) nozzles set on a U-boom $80 \mathrm{~cm}$ apart and two TXVS2 (white) nozzles positioned $35 \mathrm{~cm}$ below these. The $80^{\circ}$ hollow cone ceramic nozzles produced very fine droplet sizes at $400 \mathrm{kPa}$.

Immediately after sprays ceased dripping from leaves, three plants from each treatment were sampled for dye recovery. All leaves were carefully removed and discarded from a single stem on each plant. Each stem was cut into three lengths of approximately $12 \mathrm{~cm}$, representing three spray zones (upper, mid and lower stem). The number of leaf scars on each stem zone was recorded and each stem zone was placed in a separate resealable plastic bag. Samples were washed in distilled water as described above. Stem sections were frozen immediately after washing and subsequently the diameters and lengths of each section were measured. Spray deposits on stems were determined as dose of dye $\left(\mu \mathrm{g} / \mathrm{cm}^{2}\right)$, normalised to $2.88 \mathrm{~kg}$ application per ha (i.e. equivalent to the nominal captan dose applied) and analysed by ANOVA to determine the significance of treatments.

The sprayed plants not used for dye recovery (10 per treatment) were dried in full sunlight for at least $1 \mathrm{~h}$ and all leaves were carefully removed approximately $4 \mathrm{~h}$ after spray application. At $24 \mathrm{~h}$ after spraying, the defoliated plants (6 per treatment) were exposed to a "moderately heavy" rain event $(9.2 \mathrm{~mm} / \mathrm{h}$ applied for a total of 18 min, providing $2.8 \mathrm{~mm}$ total rain). All plants were left under cover to dry for $24 \mathrm{~h}$ post-rain, prior to sampling for captan residue analysis. The four plants per treatment that were not rained on served as pre-rain controls for captan spray deposits. All sprayed leaf scars on each stem were sampled $48 \mathrm{~h}$ after initial spraying. Sampling was undertaken using a leather punch with a hole size of $3.5 \mathrm{~mm}$ diameter. It was impossible to sample scars without taking some surrounding bark tissue but this was minimised as much as possible. The punch sampled only a partial core through the stem, and the core was then trimmed with a blade to approximately $3 \mathrm{~mm}$ thick so that the sample consisted primarily of surface tissue. All scars from each plant were sampled into a single vial and the total number recorded. All tissue samples, plus tank samples of all spray treatments, were stored frozen until analysed for captan residues.

\section{RESULTS AND DISCUSSION}

Apple stems are very easy-to-wet and spray retention on such targets is known to benefit little from adjuvants (Gaskin et al. 2005). Dye recoveries confirmed adjuvants had no effect 
on sprays retained on the defoliated apple stem wood in this study (Table 2) and there were no marked differences in spray retention due to adjuvants on spurs or on leaf scars.

The retention of captan sprays, as determined by residue analyses, confirmed deposits of captan (no rain) on leaf scars (Table 3 ) and spurs (data not presented) varied more widely than dye recoveries (Table 2). Residues and dye recoveries were quite similar for captan alone and with addition of the pinene adjuvants (Umbrella, NuFilm-17 and VaporGard), while dye recoveries were always much lower than residues with the superspreader-type adjuvants (Bond Xtra, DuWett WeatherMax and Gro-Wet). This is likely due to better spreading and faster drying time of the super-spreader sprays on the "rough" spur and leaf scar surfaces. Once dry, the efficiency of recovery of the dye in these sprays from rough surfaces may have been lower than for the slow-drying captan and pinene sprays. Dye recoveries (wash-offs) are normally undertaken immediately after spraying and before sprays have dried (Gaskin \& Steele 2009), but it was not possible in this study to harvest spurs while wet because significant loss of spray volume could have occurred.

Retained residues (no rain) were generally highest with the superspreader type adjuvants and lowest with the pinene polymer type adjuvants, which were no different to captan alone (Table 3 ). The pinene adjuvants are known to have less effect on improving spray retention compared to the superspreader/latex stickers (Gaskin \& Steele 2009). Light rain had little effect on residues on leaf scars (Table 3 ) and spurs (data not presented). While heavy rain reduced residues by approximately $22 \%$ overall, captan was well retained even in the absence of any adjuvant, suggesting the rough surface of

Table 2 Normalised spray deposits ( $1.44 \mathrm{~kg}$ dye/ha) on stems, spurs and leaf scars.

\begin{tabular}{lcccc}
\hline & Use rate & \multicolumn{3}{c}{ Normalised dye deposits } \\
\cline { 3 - 5 } Adjuvant & $(\mathrm{ml} / \mathrm{ha})$ & Stem $\left(\mu \mathrm{g} / \mathrm{cm}^{2}\right)$ & $\mu \mathrm{g} / \mathrm{spur}$ & $\mu \mathrm{g} / \mathrm{leaf} \mathrm{scar}^{2}$ \\
\hline Nil & - & $5.00 \mathrm{a}^{1}$ & $13.5 \mathrm{a}$ & $2.14 \mathrm{a}$ \\
Bond Xtra & 500 & $5.02 \mathrm{a}$ & $10.4 \mathrm{ab}$ & $1.89 \mathrm{a}$ \\
Du-Wett WeatherMax & 500 & $4.68 \mathrm{a}$ & $10.2 \mathrm{ab}$ & $1.71 \mathrm{a}$ \\
Gro-Wet & 300 & $4.91 \mathrm{a}$ & $10.5 \mathrm{ab}$ & $1.90 \mathrm{a}$ \\
Umbrella & 300 & $5.11 \mathrm{a}$ & $9.4 \mathrm{ab}$ & $1.76 \mathrm{a}$ \\
Nu-Film-17 & 300 & $5.24 \mathrm{a}$ & $9.7 \mathrm{ab}$ & $1.60 \mathrm{a}$ \\
VaporGard & 1000 & $5.47 \mathrm{a}$ & $8.6 \mathrm{~b}$ & $1.60 \mathrm{a}$ \\
\hline
\end{tabular}

${ }^{1}$ Means within columns sharing common postscripts are not significantly different $(\mathrm{P}=0.05)$.

${ }^{2}$ Deposits per scar estimated from total deposit per spur divided by the total number of leaf scars on each spur sample.

Table 3 Normalised mean residues (for $1.44 \mathrm{~kg}$ captan/ha) on leaf scars, expressed as mean mass $(\mu \mathrm{g}) /$ leaf scar.

\begin{tabular}{lclllc}
\hline Adjuvant & $\begin{array}{c}\text { Use rate } \\
(\mathrm{ml} / \mathrm{ha})\end{array}$ & no rain & light & heavy & Treatment mean \\
\hline Nil & - & $1.89 \mathrm{cde}^{1}$ & $1.97 \mathrm{cde}$ & $1.25 \mathrm{e}$ & $1.7 \mathrm{BC}$ \\
Bond Xtra & 500 & $3.90 \mathrm{a}$ & $3.47 \mathrm{ab}$ & $2.54 \mathrm{bcd}$ & $3.3 \mathrm{~A}$ \\
Du-Wett WM & 500 & $2.93 \mathrm{abc}$ & $3.87 \mathrm{a}$ & $2.80 \mathrm{abc}$ & $3.2 \mathrm{~A}$ \\
Gro-Wet & 300 & $2.19 \mathrm{cde}$ & $2.53 \mathrm{bcd}$ & $1.70 \mathrm{cde}$ & $2.1 \mathrm{~B}$ \\
Umbrella & 300 & $1.50 \mathrm{de}$ & $1.79 \mathrm{cde}$ & $1.26 \mathrm{e}$ & $1.5 \mathrm{BC}$ \\
Nu-Film-17 & 300 & $1.55 \mathrm{de}$ & $1.29 \mathrm{e}$ & $1.09 \mathrm{e}$ & $1.3 \mathrm{C}$ \\
VaporGard & 1000 & $1.31 \mathrm{e}$ & $1.10 \mathrm{e}$ & $1.19 \mathrm{e}$ & $1.2 \mathrm{C}$ \\
\hline Rain mean & $2.18 \mathrm{a}^{2}$ & $2.29 \mathrm{a}$ & $1.69 \mathrm{\beta}$ & \\
\hline
\end{tabular}

${ }^{1}$ Means in columns sharing common letters are not significantly different $(\mathrm{P}=0.05)$.

${ }^{2}$ Means within row sharing common symbols are not significantly different $(\mathrm{P}=0.05)$. 
bare spurs and leaf scars protected residues from rain wash-off. The effect of adjuvants was highly significant $(\mathrm{P}<0.0001)$, but this was mainly due to differences in initial deposits, not rainfastness per se. The latex stickers, Du-Wett Weathermax and Bond Xtra, provided highest residues after both rain events (Table 3). The addition of GroWet, Umbrella, Nu-Film-17 or VaporGard to captan sprays made no difference to post-rain deposits (after both light and heavy rain), at the adjuvant concentrations used.

Apple foliage is slightly more difficult-to-wet than stem tissue but still classified as easy-towet (Gaskin et al. 2005). However, intact foliage on plants provides a physical barrier to sprays contacting stem surfaces and in such cases, adjuvants can have very beneficial effects on spray deposition and coverage of target surfaces. In the second trial, adjuvant concentrations were not optimised for retention on leaves, and spray run-off from that surface was observed to occur with the two superspreader-type adjuvants (Du-Wett Weathermax and Gro-Wet), but not with captan alone or with the addition of $\mathrm{Nu}$ Film-17. The superspreader adjuvants increased dye deposits on stems 4-5 fold compared to captan sprays alone, while there was no increase in dye deposits on stems with Nu-Film-17 (Table 4). It is concluded the superspreader sprays were redistributed by run-off from leaf capture surfaces onto the "sheltered" stem surfaces. It is probable these sprays accumulated preferentially around the hairy buds associated with leaf nodes and this would likely act as a reservoir from which captan was redistributed onto leaf scars by rain.
The redistribution of captan deposits with rain, onto fresh leaf scars, was determined by residue analyses. Runoff with the superspreader adjuvants deposited approximately seven-fold higher residues initially (pre-rain) around leaf nodes (Table 4). Nu-Film-17 (pinene) spray residues were no different to captan alone. There was a significant interaction between treatment and rain $(\mathrm{P}<0.005)$. Post-rain, the superspreaders reduced residues compared to pre-rain, but were still three-fold higher than captan due to initial high deposits (Table 4). Run-off (or redistribution) of re-wetted residues is a likely scenario with the higher adjuvant concentrations used in this trial, due to their extreme superspreading properties (Stevens 1993). It is probable captan residues would be redistributed onto leaf scars with run-off from surrounding tissue. There was evidence of more runoff with the non-latex superspreader Gro-Wet than with the latex sticker Du-Wett WeatherMax, as would be expected.

The addition of Nu-Film-17 to sprays had no effect on captan residues, either pre- or post-rain (Table 4). In this and the nil adjuvant sprays, postrain residues were similar to pre-rain. The slight numerical increase may be due to minor run-off from surrounding stems and accumulation on "rough" scars, but any substantial redistribution in rain appears unlikely with these treatments.

\section{CONCLUSIONS}

Retention of captan sprays on bare spurs and fresh leaf scars was increased with the use of organosilicone-latex sticker adjuvants only. Light

Table 4 Normalised mean dye deposits and captan residues (for $2.88 \mathrm{~kg} / \mathrm{ha}$ of each applied) on leaf scars in Trial 2.

\begin{tabular}{|c|c|c|c|c|c|c|}
\hline \multirow[b]{2}{*}{ Adjuvant } & \multirow{2}{*}{$\begin{array}{l}\text { Use rate } \\
\text { (ml/ha) }\end{array}$} & \multirow{2}{*}{$\begin{array}{c}\text { Mean (dye) } \\
\text { deposits on } \\
\text { stems }\left(\mu \mathrm{g} / \mathrm{cm}^{2}\right)\end{array}$} & \multirow{2}{*}{$\begin{array}{c}\text { Number } \\
\text { of scars/ } \\
\text { stem }\end{array}$} & \multicolumn{2}{|c|}{$\begin{array}{l}\text { Mean mass ( } \mu \text { g captan) } \\
\text { /leaf scar }\end{array}$} & \multirow{2}{*}{$\begin{array}{c}\text { Post-rain as } \\
\% \text { of } \\
\text { pre-rain } \\
\end{array}$} \\
\hline & & & & Pre rain & Post rain & \\
\hline Nil & - & $2.45 \mathrm{~b}^{1}$ & 57 & $0.14 \mathrm{c}$ & $0.19 c$ & 136 \\
\hline Du-Wett WM & 1000 & $12.61 \mathrm{a}$ & 56 & $1.09 \mathrm{a}$ & $0.67 \mathrm{~b}$ & 62 \\
\hline Gro-Wet & 600 & $10.60 \mathrm{a}$ & 54 & $1.00 \mathrm{a}$ & $0.52 \mathrm{~b}$ & 52 \\
\hline Nu-Film-17 & 600 & $2.97 \mathrm{~b}$ & 57 & $0.20 \mathrm{c}$ & $0.27 \mathrm{c}$ & 135 \\
\hline \multicolumn{4}{|c|}{ Rain mean } & $0.610 \mathrm{c}$ & 0.413 & \\
\hline
\end{tabular}

${ }^{1}$ Means within columns sharing common letters are not significantly different $(\mathrm{P}=0.05)$.

${ }^{2}$ Means within row sharing common symbols are not significantly different $(\mathrm{P}=0.05)$. 
rain had no effect on captan spray residues on these targets, while heavy rain could reduce residues. Adjuvants could increase captan residues following rainfall but this was due to their effects on initial spray retention rather than rain-proofing per se. Thus, Du-Wett WeatherMax and Bond Xtra provided highest captan residues after rain events and significantly more than a captan spray without adjuvant.The addition of Gro-Wet, Umbrella, Nu-Film-17 and VaporGard adjuvants provided no rain proofing of captan residues on bare spurs and fresh leaf scars.

On foliated trees, retention of captan sprays on stem wood and around leaf nodes was increased by up to seven-fold with the use of superspreader type adjuvants, Du-Wett WeatherMax and Gro-Wet. This was attributed primarily to redistribution of spray by runoff from leaves. While the superspreader-type adjuvants reduced captan residues on leaf scars after a moderate rain event, high initial spray deposits resulted in post-rain residues three-fold higher than a captan spray alone suggesting redistribution of captan onto exposed leaf scars in rain is likely with these adjuvants. Nu-Film-17 adjuvant had no effect on the retention of captan sprays on stem wood or around leaf nodes, nor on leaf scar residues post-rain.

\section{ACKNOWLEDGEMENTS}

Thanks to Johnny Appleseed Ltd for providing apple shoots and to Rory Roten from Lincoln Agritech for assistance with shoot collection. Kevin Steele, Rebecca van Leeuwen, David Horgan, Alison Forster and Justin Nairn
$\left(\mathrm{PPC}_{\mathrm{NZ}}\right)$ provided technical assistance. The three companies named herein kindly provided adjuvant samples. The project was funded by the Ministry of Primary Industries Sustainable Farming Fund and Pipfruit New Zealand Inc. (SFF13-040) via a sub-contract with The New Zealand Institute of Plant \& Food Research Ltd.

\section{REFERENCES}

Anonymous 2009. UC Pest Management Guidelines for European Canker on apple. http://www.ipm.ucdavis.edu/PMG/r4100111. html\#REFERENCE (accessed 15 April 2014).

Anonymous 2014. European Standard EN 15662: Determination of pesticide residues using GC-MS and/or LC-MS/MS following acetonitrile extraction/partitioning and clean-up by dispersive SPE - QuEChERSmethod. http://www.en-standard.eu/ (accessed 15 May 2014).

Gaskin RE, Steele KD, Forster WA 2005. Characterising plant surfaces for spray adhesion and retention. New Zealand Plant Protection 58: 179-183.

Gaskin RE, Steele KD 2009. A comparison of sticker adjuvants for their effects on retention and rainfastening of fungicide sprays. New Zealand Plant Protection 62: 339-342.

Scheper RWA, Fisher BM 2010. Comparing methods to determine European canker resistance in apple tree accessions. New Zealand Plant Protection 63: 280.

Stevens PJG 1993. Organosilicone surfactants as adjuvants for agrochemicals. Pesticide Science 38: 103-122. 